\title{
Combined effects of hyperthermia and chemotherapy on the regulate autophagy of oral squamous cell carcinoma cells under a hypoxic microenvironment
}

\author{
Fan Shi ${ }^{1,2}$, Dan Luo ${ }^{1,2}$, Xuexiao Zhou ${ }^{1,2}$, Qiaozhen Sun ${ }^{1,2}$, Pei Shen ${ }^{1,2}$ and Shengzhi Wang ${ }^{2,3}{ }^{凶}$ \\ (c) The Author(s) 2021
}

\begin{abstract}
Autophagy has a complex dual role in tumor survival or cell death owning to that is an evolutionarily conserved catabolic mechanism and provides the cells with a sustainable source of biomolecules and energy for the maintenance of homeostasis under stressful conditions such as tumor microenvironment. Hyperthermia is a rapidly growing field in cancer therapy and many advances have been made in understanding and applying the mechanisms of hyperthermia. The shallow oral and maxillofacial position and its abundant blood supply are favorable for the use of hyperthermia. However, the relationship between hyperthermia and autophagy has not been examined of oral squamous cell carcinoma (OSCC) in the tumor hypoxia microenvironment. Here, the expression level of autophagy relative genes is examined to explore autophagy effect on the responses of hyperthermia, hypoxia, and innutrition tumor microenvironment. It is founded that hyperthermia and hypoxia cause autophagy in starvation conditions; further, in hypoxia and innutrition tumor microenvironment, hyperthermia combines YC-1 and 3-MA could inhibit HIF-1a/BNIP3/ Beclin 1 signal pathway and decrease the secretion of HMGB1; moreover, the cell apoptosis rate increases with an inhibited of cell migration capacity. Thus, the present study demonstrated that combined use of YC-1 and 3-MA might increase the death of tumor cells in physiological and hyperthermic conditions, which could be relevant with the inhibition of autophagy in OSCC tumor cells under hypoxia microenvironment in vitro, which offers new insight into the therapy of OSCC and its application in treating others study carcinomas.
\end{abstract}

Cell Death Discovery (2021)7:227; https://doi.org/10.1038/s41420-021-00538-5

\section{INTRODUCTION}

Oral squamous cell carcinoma (OSCC) accounts for more than $95 \%$ of all head and neck cancer and is an aggressive group of tumors characterized by high rates of regional lymph node metastasis and local recurrence, less than $50 \%$ of patients will survive for 5 years [1]. OSCC often leads to patients with maxillofacial deformities and affects patients' esthetics and quality of life. The mainstays of therapeutic schedules for OSCC comprises surgery, radiotherapy, chemotherapy, or a combination of these modalities depending on the extent of the disease, which is associated with a substantial morbidity and toxicity rate $[2,3]$. However, the strategies above have some defects, conventional surgical affects maxillofacial morphology and esthetic, chemotherapy exhibits many sideeffects leading to an increase in the toxicity profile among OSCC patients. OSCC as a solid tumor, cancer cells proliferate rapidly and form large solid tumor masses, leading to obstruction and compression of the blood vessels surrounding these masses these abnormal blood vessels do not function sufficiently and generate poor $\mathrm{O}_{2}$ supply to the central tumor regions, and the levels of oxygenation within the same tumor are highly variable from one area to another and can change over time [4, 5], therefore, hypoxia (Hy) is a crucial microenvironment condition for tumor pathophysiology and tumor metastasis. As an adaptive response to hypoxic stress, hypoxic tumor cells activate several survival pathways to carry out their essential biological processes compared with normal cells. The hypoxia-inducible factor-1a (HIF-1a) is one crucial facilitator for energy adaption and oxygen metabolic stress in hypoxia and nutrition deficiency tumor environment, and functions as a general regulator of tumor aggressiveness and metastasis as well $[4,6,7]$.

Hyperthermia (HT) is a potent radiosensitizer, which sensitizes tumor cells to radiation by inhibiting DNA repair and increasing the aggregation of damaged nuclear proteins [8, 9]. Furthermore, hyperthermia-related elevated blood flow and vascular permeability in the heated tumor region also promote higher intratumor and peritumor drug concentrations to improve the efficacy of chemotherapy [9-11]. And which in combination with radiotherapy, enforces immunomodulation akin to "in situ tumor vaccination" [12]. Therefore, hyperthermia acts as a complement of radiotherapy, chemotherapy, and molecular targeted monotherapy.

Autophagy is a cellular pathway that presents only in eukaryotic cells to degrade the aged and damaged organelles as well as misfolded proteins. It functions as a recycling program to provide biofuel to cells from degraded macromolecules to maintain

\footnotetext{
${ }^{1}$ School of Stomatology of Qingdao University, Qingdao, China. ${ }^{2}$ Department of Oral and Maxillofacial Surgery, The Affiliated Yantai Yuhuangding Hospital of Qingdao University, Yantai, China. ${ }^{3}$ Institute for Translational Medicine, Department of Stomatology, The Affiliated Hospital of Qingdao University, Qingdao, China. ${ }^{凶}$ email: wangsz916@163.com Edited by Ivano Amelio
} 
sufficient ATP production for survival and is a key component in maintaining homeostasis of the cellular environment [13]. Depending on the exact cell type and conditions, it either acts as a protagonist or an antagonist of apoptosis [14]. Autophagy also plays a crucial role in cancer pathophysiology. It is believed to prevent cancer development in normal tissue, but when in the severe tumor microenvironment of solid malignancies, as an adaptive response, which helps cells recycle metabolites and organelles in order to survive and protect cancer cells within an already established tumor from the shortage of nutrients and hypoxic conditions $[14,15]$. Previous studies have shown that initiating triggers for death in heat-shocked cells include induction of physiological cascades; thermal protein unfolding and aggregation; necrosis that occurred at extremely elevated temperatures [16]. The ability of hyperthermia to augment radiation therapy and chemotherapy has been demonstrated in clinical oncology as evidenced in many phases II and III trials [17, 18]. However, tumor cells possess homeostatic responses to reduce heat-shockinduced cell death, which involves cell cycle arrest and transient induction of the transcription of genes encoding molecular chaperones and heat shock proteins (HSPs) [19]. In short, hyperthermia induces the expression of HSPs and inhibits DNA damaged to repair, whereas DNA damage, hyperthermia, and HPSs evoke autophagy, which was associated with facilitated cell survival and decreased programmed cell death [16, 19-21]. Furthermore, cellular damage caused by heating can be repaired and reversed by autophagy, resulting in incomplete cell necrosis $[21,22]$. HMGB1 is a late inflammatory mediator associated with sepsis, malignancy, and immune disease [23], which is passively released by necrotic tissues or actively secreted by stressed cells [24]. Intracellularly, HMGB1 is involved in DNA repair, transcription, and recombination as well in the regulation of apoptosis/ autophagy balance. Once secreted, it participates in a variety of processes such as inflammation, proliferation, differentiation, migration, invasion, and tissue regeneration [25]. Heat shock stress from hyperthermia can lead to cell necrosis, and literature reported necrosis-inducing anticancer drugs to enhance high mobility group box-1 protein (HMGB1) released during cell necrosis [26], and HMGB1 regulates autophagy [23].

Therefore, HSPs and autophagy are two controllers of cellular proteostasis. Under stressful cellular conditions, such as hyperthermia, hypoxia, and energy deficiency, these two mechanisms are likely to complement each other [16]. However, it remains unknown whether hyperthermia-induced autophagy facilitates cell survival or accelerates cell death in hypoxia and nutritiondeficient tumor microenvironment of human OSCC. Hence, we aimed to investigate the relationship between hyperthermia and autophagy in hypoxia and nutrition-deficient tumor microenvironment of human OSCC. Meanwhile, the underlying mechanism was examined. This study might provide a novel promising therapeutic regiment for human OSCC.

\section{RESULTS}

HIF-1a and Beclin 1 expression levels increased in OSCC tissues The clinical significance of HIF-1a and Beclin1 in OSCC patients was evaluated by analyzing the expression level of HIF-1a and Beclin1 in 80 OSCC tissues and pare-cancer tissue (tumor margin adjacent normal tissues) by the scoring of IHC (Fig. 1). HIF-1a is mainly located in the cell nucleus while Beclin 1 is mainly located in the cell membrane and cytoplasm with a small amount in the cell nucleus. In this study, we observed that HIF-1a and Beclin1 were expressed both in cancer tissue and adjacent normal tissues. By multiplying the score of staining intensity and percentage of positive cells of each tissue section, we found that HIF-1a and Beclin1 were both highly expressed in OSCC tissues compared with pare-cancer tissue (tumor margin adjacent normal tissues) $(p<0.05$, Supplementary Table 1$)$. Besides, the high expression level of HIF-1a and Beclin1 was associated with poor cell differentiation, lymph node metastasis, advanced pathological TNM stage, and large tumor size $(p<0.05$, Table 1$)$, but was not correlated with gender or age (Fig. 2).

\section{Establishment of hypoxic microenvironment}

Low oxygen-induced hypoxia is the optimal hypoxia model. However, induction of chemical hypoxic conditions using $\mathrm{CoCl}_{2}$ allows the researcher to open the culture container many times while maintaining a stable level of HIF-1a. The IC50 values for $\mathrm{CoCl}_{2}$ in Cal-27 and SCC-15 cells were $108.3 \mu \mathrm{M}$ and $99.68 \mu \mathrm{M}$, respectively, as determined by the CCK-8 cell viability assay. Therefore, we used $100 \mu \mathrm{M} \mathrm{CoCl}_{2}$ in free-serum RPIM 1640 to achieve the hypoxia and starvation microenvironment for the subsequent experiments (Supplementary Table 3 and Fig. S1). Our results showed that compared with the untreated control group, stable mRNA and protein expression of HIF-1a could be induced in Cal-27 and SCC-15 cells in a dose-dependent manner by $\mathrm{CoCl}_{2}$ under normoxia, as measured by qRT-PCR and Western blot respectively, which demonstrated the successful establishment of the hypoxic tumor microenvironment (Fig. 3A-C). Compared with the control group, Cal-27 and SCC-15 cells both presented a significant augment in cell migration under the hypoxia microenvironment $(p<0.05$, Fig. 2). This result suggested that the hypoxia microenvironment facilitated HIF-1a expression and promoted cell migration. In general, the results from the two cell lines (Cal-27 and SCC-15) showed a similar tendency.

\section{Hyperthermia induced autophagy of OSCC cells in the hypoxic microenvironment}

To clarify the relationship between hypoxia, hyperthermia, and autophagy, we tested proteins related to autophagy signaling pathway by Western blot and qRT-PCR in Cal-27 and SCC- 15 cells, and found that HIF-1a and BNIP3 were hardly expressed in the untreated control group and "HT" group (hyperthermia treatment alone), and there was no statistical difference in the expression of HIF-1a and BNIP3 in HT group compared the control group $(p>$ 0.05 , Fig. 4, Supplementary Fig. S2). This indicated that HIF- $1 a$ and BNIP3 were not expressed in abundance under normal oxygen conditions, and hyperthermia could not induce the expression of HIF-1a and BNIP3 in normoxia conditions. The expression of autophagy-related genes such as Beclin 1 and LC3II were higher in the HT group compared to the control group $(p<0.05$, Fig. 4, Supplementary Fig. S2), showing that Beclin1 and LC3II were expressed under constant oxygen condition and hyperthermia promoted Beclin 1 and LC3II expression. Besides, the expression of P62 protein sharply decreased in the HT group compared to the control group ( $p<0.05$, Fig. 4, Supplementary Fig. S2). Taken together, the results showed that hyperthermia could induce autophagy under normal oxygen conditions. However, the expression level of HIF-1a, BNIP3, Beclin1, LC3II significantly increased in the Hy group (hypoxia treatment alone) and the "HT + Hy" group (combined hypoxia and hyperthermia treatment) compared to the control group and HT group $(p<0.05)$. On contrary, the expression of P62 sharply decreased in the Hy group and "HT + Hy" group compared to the control group and HT group $(p<0.05)$, what is more, we found that compared with the Hy group, the expression of HIF-1a, BNIP3, Beclin1, LC3II were significantly higher, whereas that of p62 proteins were remarkably lower in the "HT $+\mathrm{Hy}$ " group $(p<0.05$, Fig. 4, Supplementary Fig. S2). In general, the results from the two cell lines (Cal-27 and SCC15) showed a similar tendency.

Hyperthermia combined chemotherapy inhibited autophagy To further investigate the correlation between hyperthermiainduced the HIF-1a/BNIP3/Beclin1 autophagy signaling pathway in hypoxia and starvation tumor microenvironment, YC-1 was used to suppress the HIF-1a-mediated autophagy pathway, and 3-MA 
HIF-1a
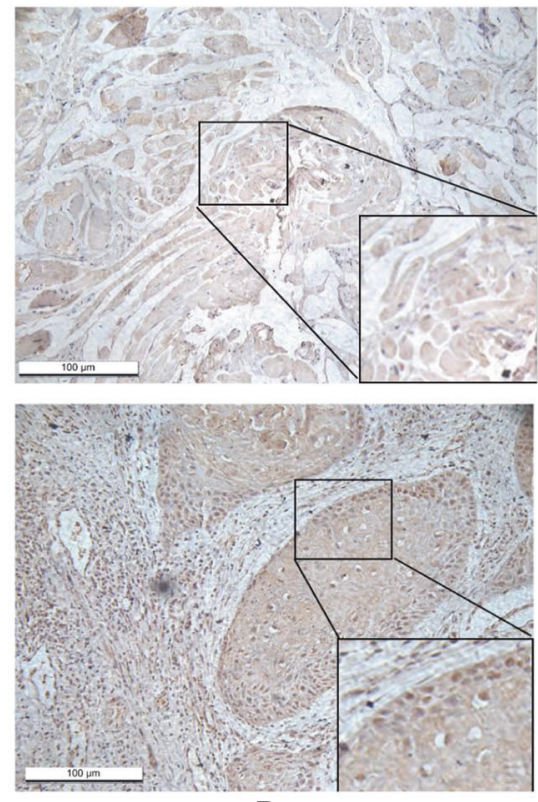

$+D$

Beclin1
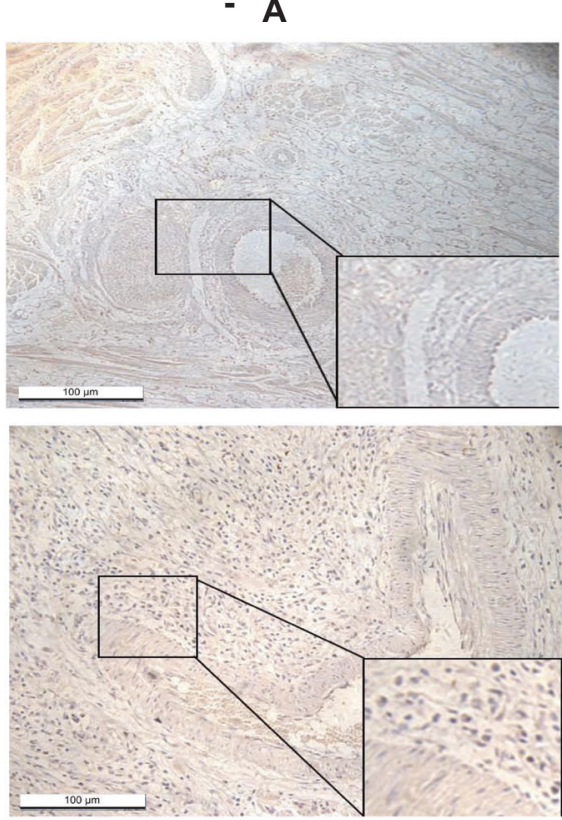

+ D
+ B
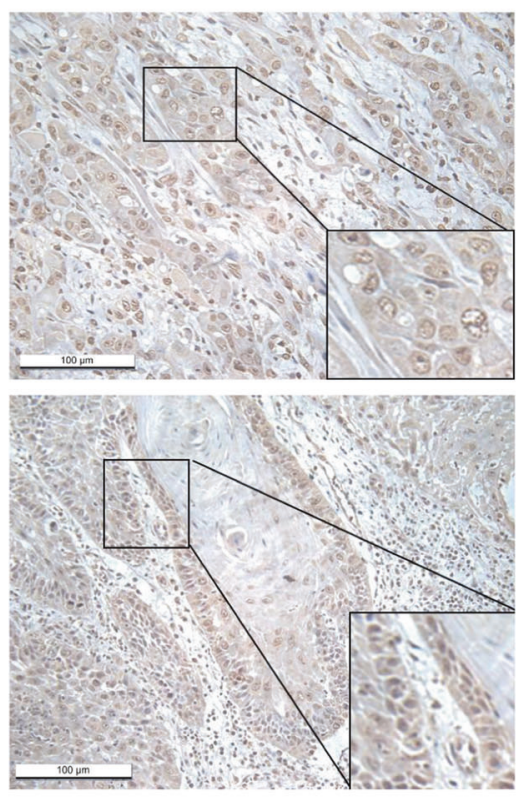

++ E

+ B
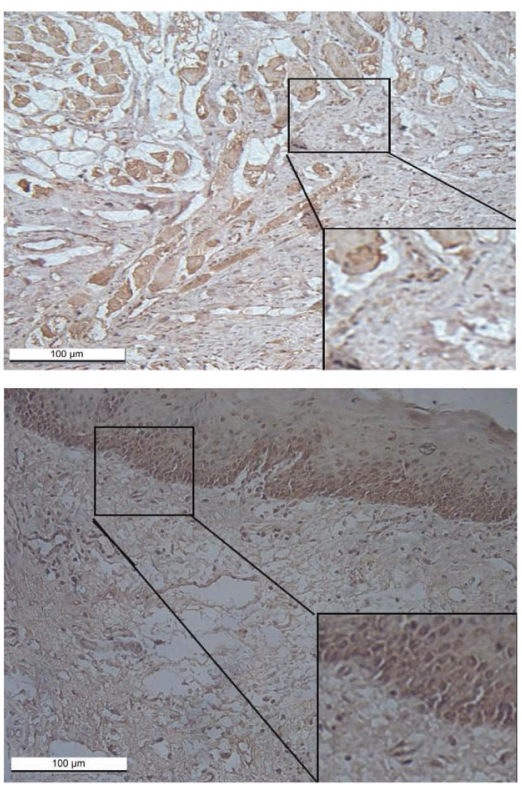

E
- C
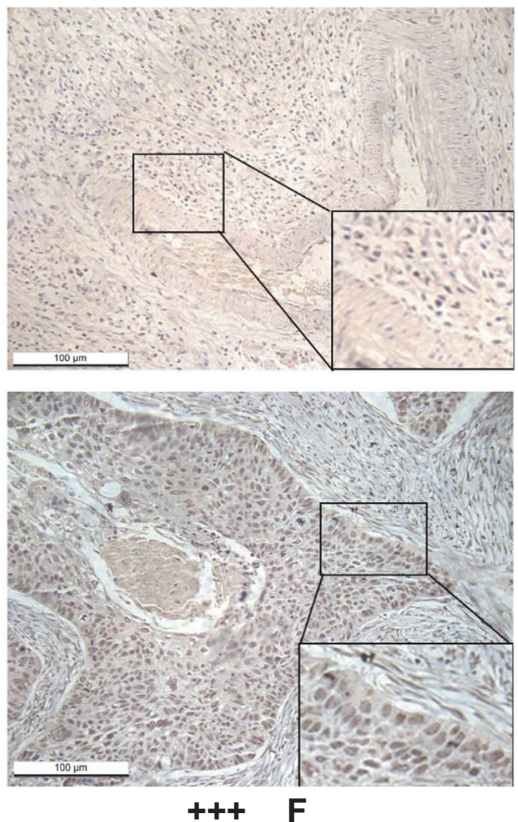

- C
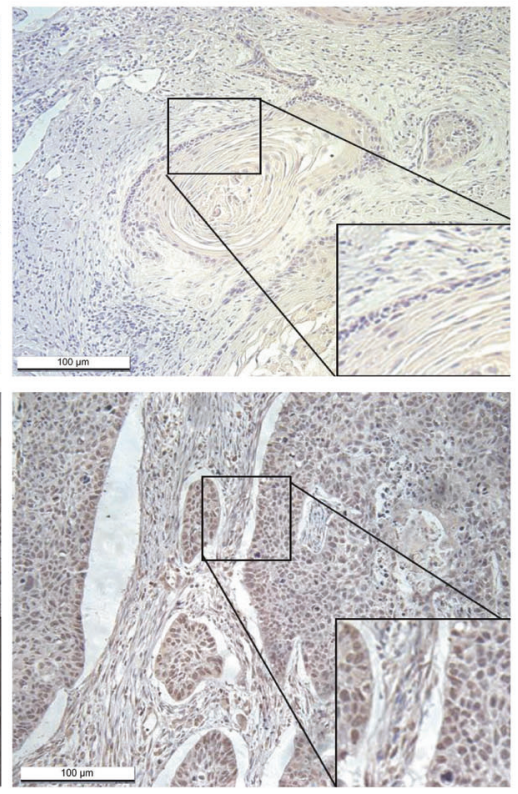

+++ $\quad F$

Fig. 1 The expression level of HIF-1a and Beclin 1 in OSCC tissues and para cancer tissues $(\times 200)$ HIF-1a was mainly expressed in the cell nucleus while Beclin1 was mainly located in the cell membrane and cytoplasm with a small amount in the cell nucleus. The positive staining of HIF-1 $\alpha$ and Beclin1 showed uniform light yellow, brownish-yellow, or tan granules. A, B Normal tissue. C-F OSCC tissues. HIF-1 $\alpha$ hypoxia-inducible factor-1 $\alpha$, Beclin1, a coiled-coil Bcl-2-interacting protein homologous, OSCC oral squamous cell carcinoma.

was used for direct inhibition of autophagy. First, the IC50 of YC-1 and 3-MA was assessed by CCK-8. The IC50 values for YC-1 in Cal27 and SCC-15 cells were $24.37 \mu \mathrm{M}$ and $34.72 \mu \mathrm{M}$, respectively (Supplementary Fig. S1, Table 4). We used $20 \mu \mathrm{M}$ for Cal-27 and $30 \mu \mathrm{M}$ for SCC-15 cells to conduct the following experiments. The IC50 values for 3-MA in Cal-27 and SCC-15 cells were $35.77 \mu \mathrm{M}$ and $30.89 \mu \mathrm{M}$, respectively (Supplementary Fig. S1, Table 5), therefore we used $35 \mu \mathrm{M}$ (Cal-27 cell) and $30 \mu \mathrm{M}$ (SCC-15 cell) in the subsequent experiments. Through PCR and Western blot analysis we found that the expression levels of HIF-1a and BNIP3 were not statistically different in the "HT + Hy" group vs. the "HT $+\mathrm{Hy}+3-$ $\mathrm{MA}^{\prime}$ group and "HT + Hy+YC-1" group vs. "HT + Hy+YC-1 + 3MA" group ( $p<0.05$, Fig. 5, Supplementary Fig. S3). Both HIF-1a and BNIP3 expressions were lower in the "HT + Hy+YC-1" group than in the "HT $+\mathrm{Hy}$ " group and "HT $+\mathrm{Hy}+3-\mathrm{MA}^{\prime}$ group and were even lower in the "HT+Hy+YC-1+3-MA" group. Reduced Beclin1 and LC3II expression levels were observed in the following groups: $\mathrm{HT}+\mathrm{Hy}+\mathrm{YC}-1+3-\mathrm{MA}<\mathrm{HT}+\mathrm{Hy}+3-\mathrm{MA}<\mathrm{HT}+\mathrm{Hy}+\mathrm{YC}-$ 
Table 1. Association between HIF-1 $\alpha$, Beclin1 expression, and the clinical as well histopathological features of patients with oral squamous cell carcinoma $(n=80)$.

\begin{tabular}{|c|c|c|c|c|c|c|c|c|c|}
\hline Variables & $\begin{array}{l}\text { Number of patients } \\
\text { (n) }\end{array}$ & $\begin{array}{l}\text { HIF-1a } \\
\text { positive } \\
\text { (n) }\end{array}$ & $\begin{array}{l}\text { HIF-1a positive } \\
\text { rate (\%) }\end{array}$ & $x^{2}$ & $p$ & $\begin{array}{l}\text { Beclin1 } \\
\text { positive } \\
\text { (n) }\end{array}$ & $\begin{array}{l}\text { Beclin1 } \\
\text { positive } \\
\text { rate (\%) }\end{array}$ & $x^{2}$ & $p$ \\
\hline \multicolumn{10}{|l|}{ Sex } \\
\hline Female & 24 & 16 & $66.67 \%$ & & & 19 & $79.17 \%$ & & \\
\hline \multicolumn{10}{|l|}{ Age, years } \\
\hline \multicolumn{10}{|l|}{ Tumor size, $\mathrm{cm}$} \\
\hline$\geq 1.5$ & 53 & 43 & $81.13 \%$ & 6.661 & 0.037 & 42 & $79.25 \%$ & 10.87 & 0.004 \\
\hline$<1.5$ & 27 & 14 & $51.85 \%$ & & & 11 & $40.74 \%$ & & \\
\hline \multicolumn{10}{|l|}{ TNM stage } \\
\hline | or II & 24 & 14 & $58.3 \%$ & 8.54 & 0.015 & 11 & $45.83 \%$ & 8.412 & 0.015 \\
\hline Moderate/poor & 51 & 39 & $76.47 \%$ & & & 36 & $70.59 \%$ & & \\
\hline \multicolumn{10}{|c|}{ Lymph node metastasis } \\
\hline Positive & 47 & 39 & $82.98 \%$ & 33.71 & 0.001 & 33 & $70.21 \%$ & 6.729 & 0.035 \\
\hline Negative & 33 & 7 & $21.21 \%$ & & & 14 & $42.42 \%$ & & \\
\hline
\end{tabular}

Table 2. Expression difference of HIF-1 $\alpha$ and Beclin1 in OSCC tissues and para cancer tissues ( $n$, \%).

\begin{tabular}{|c|c|c|c|c|c|c|c|c|c|}
\hline \multirow[t]{2}{*}{ Group } & \multirow[t]{2}{*}{ Number } & \multicolumn{2}{|c|}{ HIF-a protein expression } & \multirow[t]{2}{*}{$x^{2}$} & \multirow[t]{2}{*}{$P$} & \multicolumn{2}{|c|}{ Beclin1 protein expression } & \multirow[t]{2}{*}{$x^{2}$} & \multirow[t]{2}{*}{$P$} \\
\hline & & negative & positive & & & negative & positive & & \\
\hline Cancer tissues & 80 & $23(28.75 \%)$ & 57 (71.25\%) & 25.42 & $P<0.01$ & $29(36.25 \%)$ & $51(63.75 \%)$ & 13.23 & $P<0.05$ \\
\hline
\end{tabular}

$1<\mathrm{HT}+\mathrm{Hy}$. Conversely, increased expression levels of P62 were observed in the following groups: $\mathrm{HT}+\mathrm{Hy}+\mathrm{YC}-1+3-\mathrm{MA}>\mathrm{HT}+$ $\mathrm{Hy}+3-\mathrm{MA}>\mathrm{HT}+\mathrm{Hy}+\mathrm{YC}-1>\mathrm{HT}+\mathrm{Hy}(p<0.05$, Fig. 5, Supplementary Fig. S3). These data indicated hyperthermia-induced autophagy through activating the HIF-1a/BNIP3/Beclin 1 signaling pathway. 3-MA had a stronger effect in inhibiting autophagy than YC-1, and combined use of 3-MA and YC-1 provided further inhibition of autophagy in OSCC cells. Therefore, we concluded that hyperthermia might not only induce autophagy through activating the HIF-1a/BNIP3/Beclin1 signaling pathway but also involve other pathways in the hypoxia and starvation microenvironment. Moreover, hyperthermia combined with chemotherapy inhibits autophagy. In general, the results from the two cell lines (Cal-27 and SCC-15) showed a similar tendency.

\section{Hyperthermia combined chemotherapy inhibited the secretion of HMGB1}

HMGB1 was translocated from the nucleus to the cytoplasm and secreted or passively released through the permeabilized plasma membrane of succumbing/dead cells. We measured the extracellular HMGB1 protein by ELISA and found that compared with the control group, the secretion of HMGB1 significantly increased with hypoxia or hyperthermia treatment alone and combined in Cal-27 and SCC-15 cells, with the protein level in the "HT $+\mathrm{Hy}$ " group $>\mathrm{HT}$ group $>\mathrm{Hy}$ group $>$ control group ( $p<0.05$, Fig. 6$)$, suggesting that hyperthermia and hypoxia promoted HMGB1 secretion under normal oxygen conditions and that hyperthermia was stronger than hypoxia in promoting HMGB1 secretion. On the contrary, the addition of 3-MA and YC-1 significantly reduced the secretion of $\mathrm{HMGB1}$, with protein level in the "HT + Hy+YC-1 + 3-MA" group $<$ "HT + Hy+3-MA" group $<" \mathrm{HT}+\mathrm{Hy}+\mathrm{YC}-1 "$ group $<$ "HT $+\mathrm{Hy}$ " group $(p<0.05$, Fig. 6). Based on the above experimental data, we concluded that hyperthermia and hypoxia might facilitate HMGB1 secretion in the starvation tumor microenvironment, and the use of chemotherapy drugs could also inhibit the secretion of HMGB1 in addition to autophagy inhibition. Therefore, we speculated that there is also a connection between HMGB1 secretion and autophagy. In general, the results from the two cell lines (Cal-27 and SCC-15) showed a similar tendency.

\section{Inhibition of autophagy reduced tumor cell migration in hypoxia and starvation microenvironment}

To determine the effect of autophagy and hypoxia on Cal-27 and SCC-15 cell migration, we performed a wound-healing assay in Cal-27 and SCC-15 cells and the results showed compared with untreated control cells, cell mobility increased in the Hy group and decreased in the HT group, which demonstrated hypoxia might promote cell migration while hyperthermia inhibits cell migration ( $p<0.05$, Fig. 2 ). In addition, the "HT + Hy" group had worse migratory ability than the "Hy" group, which demonstrated that hyperthermia could inhibit cell migration whether in normoxia or hypoxia conditions. Compared with the "HT + Hy" group, the cell migration of the "HT + Hy+3-MA" group, "HT + Hy+YC-1" group, and "HT + Hy+YC-1 + 3-MA" group were all significantly reduced ( $p<0.05$, Fig. 2$)$, and the "HT $+\mathrm{Hy}+\mathrm{YC}-$ $1+3-M^{\prime \prime}$ group had the strongest inhibition of cell migration, which indicated that inhibiting autophagy might reduce tumor cell migration in hypoxia microenvironment. However, there was no 


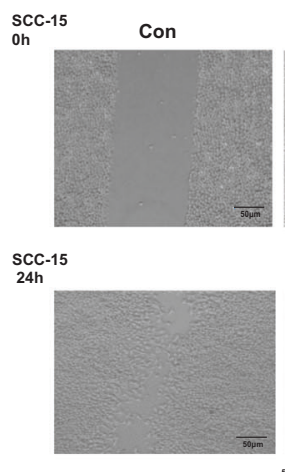

HT
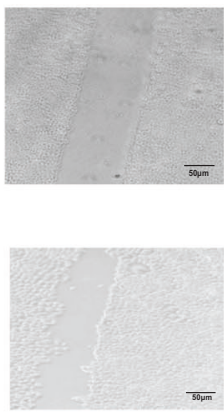

$\mathrm{HT}+\mathrm{Hy}+3-\mathrm{MA}$
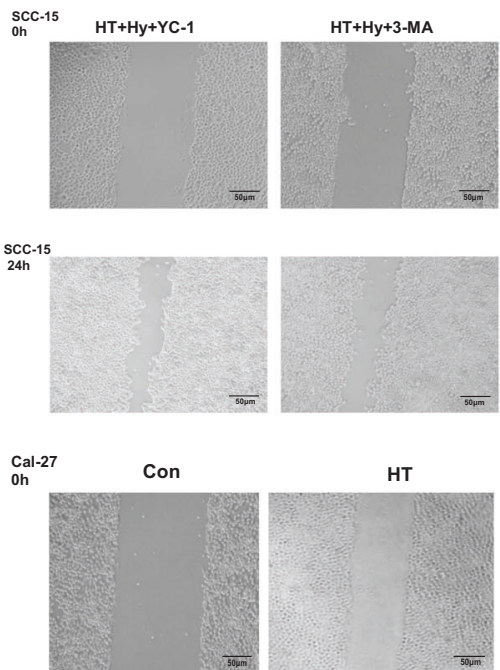

HT

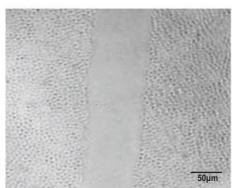

Cal-2
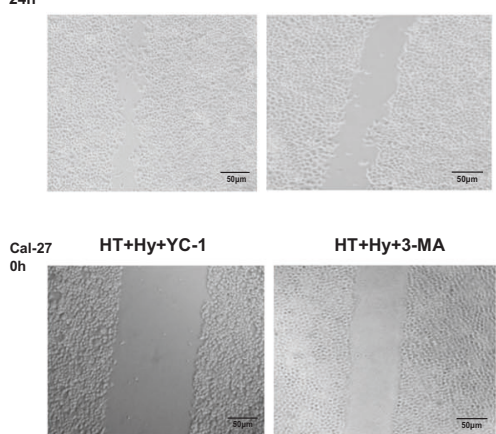

HT+Hy+3-MA

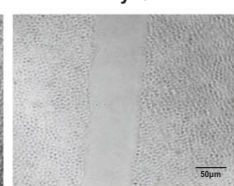

Cal-27
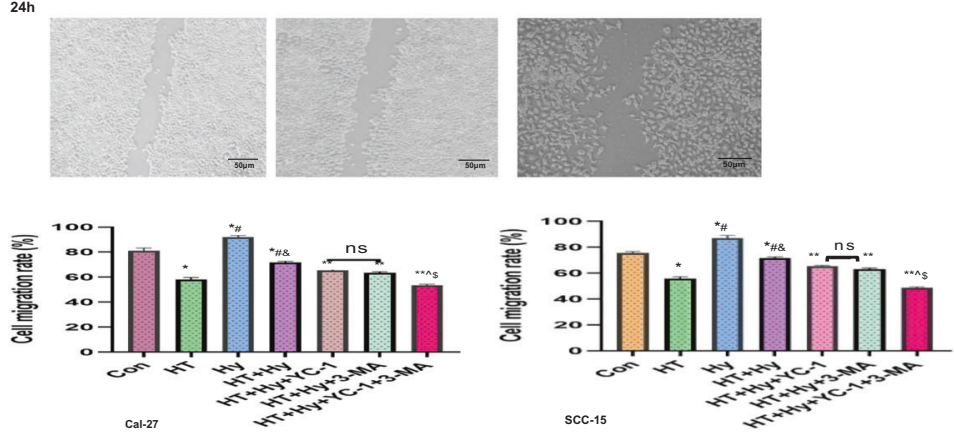

Fig. 2 HT combined YC-1, 3-MA alone or both inhibited the migration of Cal-27 and SCC-15 cells in hypoxia and starvation microenvironment, as determined by wound healing assay. Magnification, $\times \mathbf{4 0 0}$. Data were expressed as the mean $\pm S E M$ from three independent experiments. Con control, HT hyperthermia, Hy hypoxia; YC-1: 3-(5'-hydroxymethyl-2'-furyl)-1-benzylindazole; 3-MA: 3Methyladenine; the histogram of cell migration rate after treatments were analyzed. ${ }^{*} p<0.05$ vs. Con group; \#p<0.05 vs. HT group; \&p<0.05 vs. Hy group; ${ }^{* *} p<0.05$ vs. HT + Hy group; $\wedge p<0.05$ vs. HT + Hy $+3-M A$ group; $\$ p<0.05$ vs. HT + Hy + YC-1 group; ns no significant difference $(p>0.05)$. 


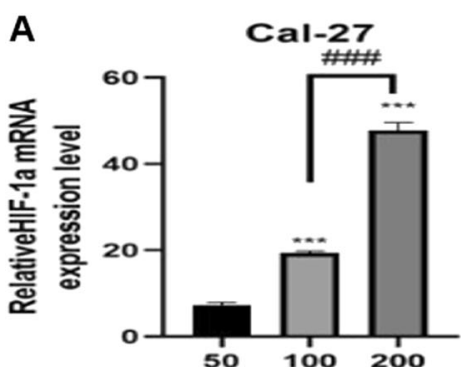

$\mathrm{Cocl}_{2}$ concentration (uM)

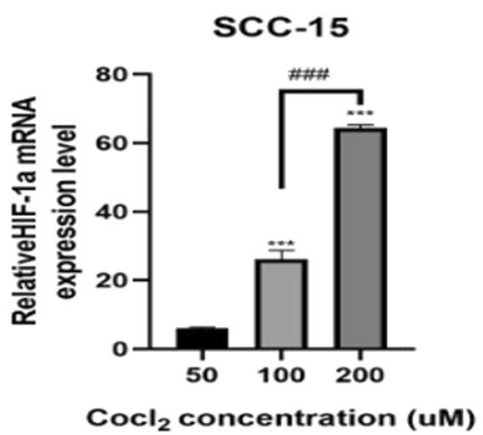

$\mathbf{B}$

\section{$\mathrm{CoCl} 2$ concentration (uM)}

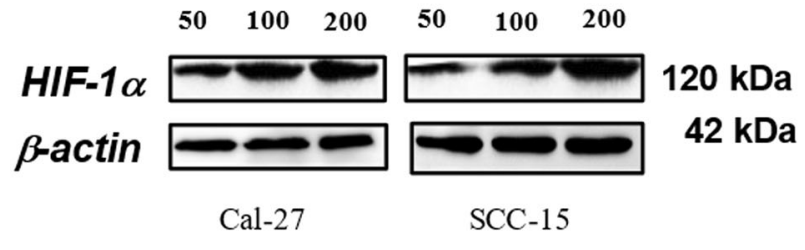

C

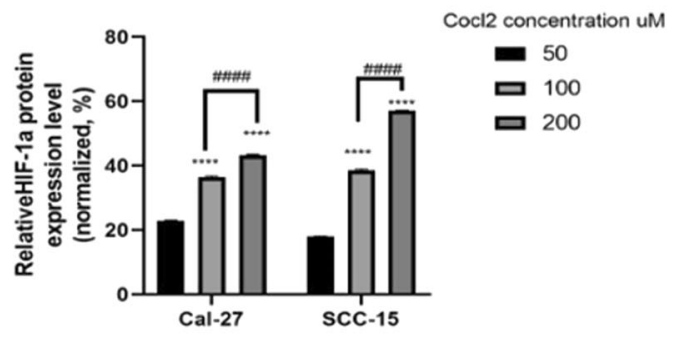

Fig. $3 \mathrm{CoCl}_{2}$ induced the mRNA and protein expression of HIF-1a to construct a hypoxic microenvironment. $\mathrm{CoCl}_{2}$ significantly induced the mRNA (A) and protein (B) and (C) expression of HIF-1 $\alpha$ in a dose-dependent manner. Cal-27 and SCC-15 cells were co-cultured with different concentrations of $\mathrm{CoCl} 2$ for $24 \mathrm{~h}$, then the mRNA and protein expression levels of HIF- $1 \alpha$ were analyzed by qRT-PCR and Western blot, which were normalized to those of $\beta$-actin. Data were expressed as the mean $\pm \mathrm{SEM}$ from three independent experiments. ${ }^{*} p<0.05$,

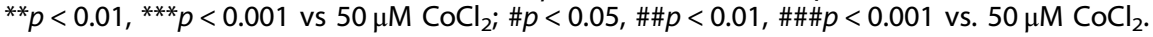

significant difference in migration between the "HT + Hy + 3-MA" group and the "HT $+\mathrm{Hy}+\mathrm{YC}-1$ " group $(p>0.05$, Fig. 2$)$. In general, the results from the two cell lines (Cal-27 and SCC-15) showed a similar tendency.

\section{Inhibition of autophagy enhanced hyperthermia-induced apoptosis in OSCC cells}

Apoptosis was investigated using flow cytometry analysis. We found that compared with the control group, the cell apoptosis rate increased in the Hy group and decreased in the HT group. Meanwhile, the cell apoptosis rate of the "HT + Hy" group was higher than the Hy group and control group ( $p<0.05$, Fig. 7), which supported the conclusion that hyperthermia significantly promoted tumor cell apoptosis at normal oxygen concentration and hypoxia condition, while hypoxia inhibited cell apoptosis in nutrition deficiency microenvironment. Besides, YC-1 and 3-MA both facilitated cell apoptosis in approximately equivalent scale ( $p$ $>0.05$ ) and combined use of both drugs had the strongest effect on cell apoptosis $(p<0.05$, Fig. 7). However, in terms of the apoptotic sensitivity of Cal-27 and SCC-15 cell lines, compared with the SCC-15 cell line, the apoptotic sensitivity of the Cal-27 cell line was lower under various treatment conditions, which may result in the cell lines have a certain resistance to various treatments. In general, the results from the two cell lines (Cal-27 and SCC-15) showed a similar tendency, namely, HT combined with chemotherapy could significantly promote OSCC cell apoptosis by inhibiting autophagy under hypoxia and nutrition deficiency microenvironment in vitro.

\section{DISCUSSION}

OSCC is the most common solid tumor in the head and neck, and a growing body of evidence indicates that the microenvironment of a solid tumor with hypoxia, low $\mathrm{PH}$, poor nutrition, poor perfusion, and abnormally high interstitial fluid pressure change the biological behavior of the tumor, which significantly reduces the effect of radiotherapy and chemotherapy and promotes tumor cell proliferation, invasion, and migration $[27,28]$. The adaptation and survival of tumor cells in heterogeneous microenvironments requires the coordination of complex pathways and mechanisms, such as hypoxia induction factor 1 (HIF-1), unfolded protein reaction (UPR), rapamycin (mTOR), and autophagy [29]. Hypoxia is a crucial microenvironment condition for solid tumor pathophysiology, HIF-1a is a key molecule that is highly expressed under hypoxia. In general, under the condition of normoxia, the biosynthesis of mitochondrial respiration and anabolism is facilitated by oncoprotein MYC, allowing cancer cells to proliferate under conditions of adequate oxygen and nutrition [30, 31]. But under hypoxia, energy metabolism is regulated by HIF-1 rather than MYC, HIF-1 is a powerful mediator of carbohydrate reprogramming from oxidative phosphorylation to glycolytic metabolism in hypoxic reactions by regulating oxygen transport (angiogenesis) and oxygen consumption (glycolysis metabolism) [32]. Metabolic pathway changes of tumor cells during hypoxia or malnutrition are considered to be a feature of cancer cells, namely metabolic reprogramming [33]. Also, when tumor cells are exposed to a stressful microenvironment, especially low $\mathrm{PH}$, low oxygen, and nutrient deficiency, autophagy is activated to cycle cellular metabolic substrate to meet their high metabolism and energy demand, as well as to suppress the body's inflammatory response induced by the tumor to prevent the cytotoxicity accumulation and to promote tumor cell survival. Therefore, autophagy constitutes a way to prolong the survival of tumor cells $[27,28,34,35]$. Therefore, HIF-1a is considered to be a potential prognostic marker of many cancers, including OSCC [36]. The formation of HIF-1a is oxygen-dependent. At the tumor margin, blood vessels grow to provide sufficient nutrients and oxygen, allowing the synthesis and rapid ubiquitin-mediated degradation within 10 min of HIF-1a under normoxia. In contrast, HIF-1a protein activity is prolonged under hypoxia [30]. Therefore, one important consequence of hypoxia is the induction of HIF-1a, which activates a series of downstream genes that facilitate tumor 


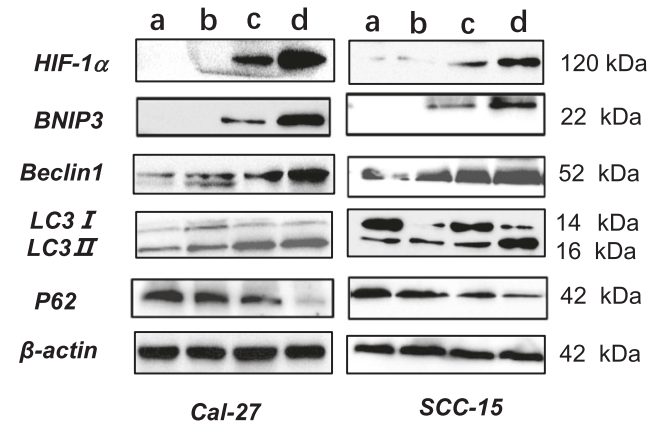

a:Con; b:HT; c:Hy; d:HT+Hy. Con: control; HT: hyperthermia; Hy: hypoxia; $H T+H y$ : hyperthermia+hypoxia.
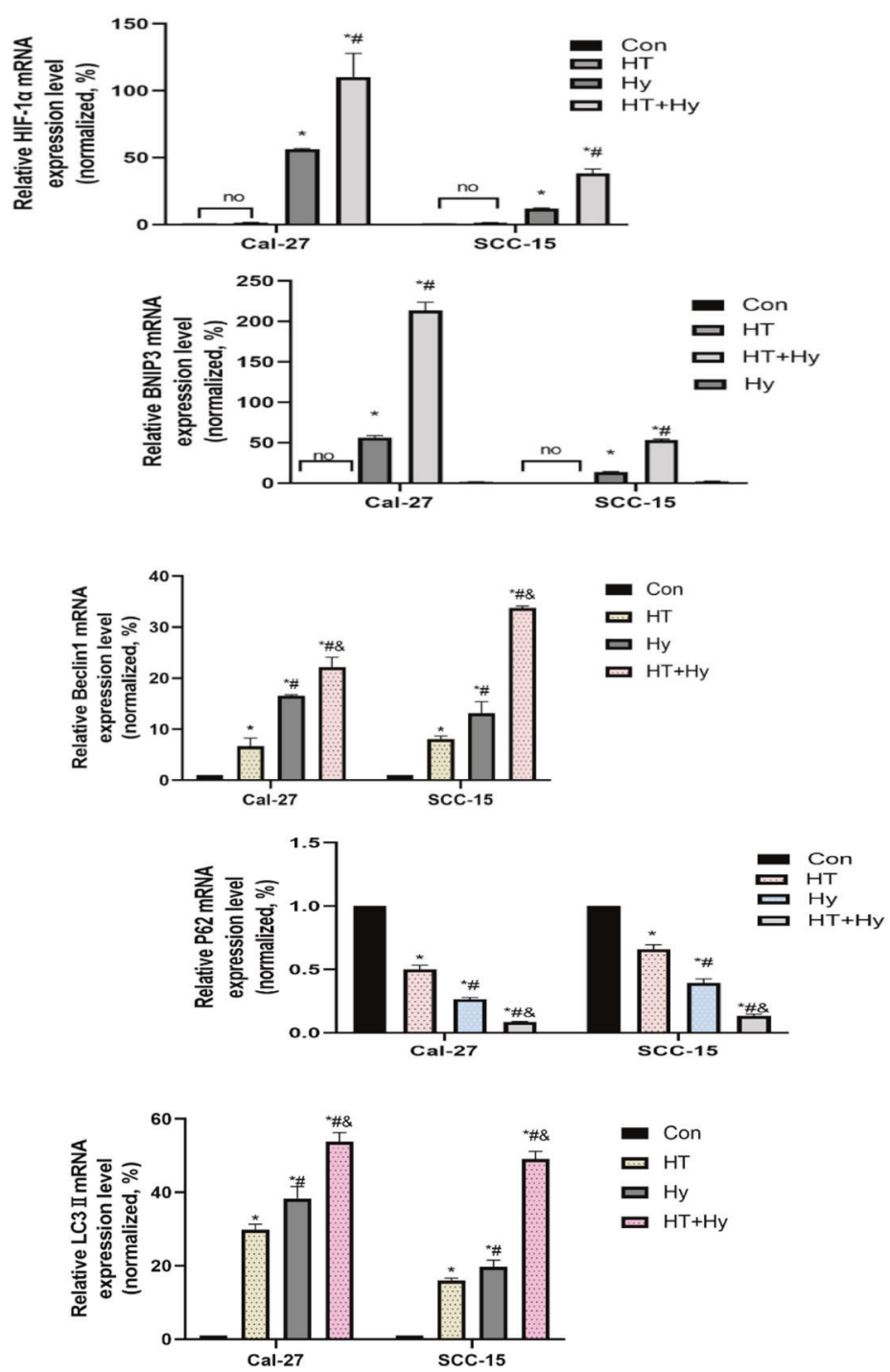

Fig. 4 Hyperthermia and hypoxia-induced the expression of autophagy hallmark proteins in OSCC cells. Cal-27 and SCC-15 cells were cultured in hypoxia conditions and were exposed to $42^{\circ} \mathrm{C}$ for $1 \mathrm{~h}$, followed by recovery at $37^{\circ} \mathrm{C}$ for $24 \mathrm{~h}$. The protein and mRNA levels of HIF$1 \alpha$, BNIP3, Beclin1, LC3-II, and p62 were analyzed by qRT-PCR and western blot and normalized to those of $\beta$-actin. Data were expressed as the mean \pm SEM from three independent experiments. a: Con; b: HT; c: Hy; d: HT + Hy. Con control, HT hyperthermia, Hy hypoxia, HT + Hy hyperthermia+hypoxia. ${ }^{*} p<0.05$ vs. Con group; $\# p<0.05$ vs. HT group; $\& p<0.05$ vs. Hy group; no: no significant difference ( $p>0.05$ ).

cell survival in the hypoxia microenvironment, such as autophagyrelated genes Beclin1 [37]. In this study, we detected the expression level of HIF-1a and Beclin 1 in 80 pairs of OSCC tissues and adjacent normal tissue, and our results suggested that HIF-1a and Beclin 1 were both highly expressed in OSCC tissues compared with normal tissues and were significantly associated with large tumor size, advanced TNM grade, high pathological grade and lymphocytic infiltration. This finding is consistent with Ribeiro et al. research results [38].

Kinds of literature have reported that autophagy is a self-degrading process and plays an indispensable role in sustaining cellular homeostasis under stress $[39,40]$. The role of autophagy in cancer is most dramatic and dynamic. In normal cells, autophagy inhibits tumor occurrence, however, in hypoxia and nutrient deficiency tumor microenvironment, autophagy promotes tumor cell survival as an alternative energy supply pathway besides the "Warburg effect". Autophagy initiation occurs under stress conditions, such as nutrient and energy deficiency, hypoxia, reactive oxygen species (ROS), protein aggregation, and production of damaged organelles [41, 42]. As is well known, the conversion of cytosolic LC3-I to LC3-II, which binds autophagic vacuoles, is the primary hallmark of autophagy. The protein p62 (also known as SQSTM1) has been reported to interact with the autophagic effector protein LC3 and to be degraded through an autophagy-lysosome pathway [43]. Therefore, activation of autophagic flux leads to a decrease in p62 and LC3-I levels and an increase in LC3-II levels. Our research showed that OSCC cells Cal-27 and SCC-15 also underwent autophagy under hypoxia conditions. In physiological conditions, Beclin-1 and Bcl-2 form a complex compound that results in inhibiting the activation of the autophagy pathway. It has been confirmed that BNIP3 is the target molecule of HIF-1a. Under hypoxia conditions, the expression of HIF-1a significantly augments, which upregulates BNIP3, and BNIP3 interacts with $\mathrm{BCl}-2$ or $\mathrm{BCl}-\mathrm{XL}$ and ultimately forms heterodimer, which will prevent the binding of $\mathrm{BCl}-2$ to Beclin-1, thereby the released Beclin-1 will activate the autophagy pathway [44]. As a result, HIF-1a/BNIP3/ Beclin-1 signaling pathway is an important way of inducing autophagy under hypoxic conditions.

Mild hyperthermia $\left(41-43^{\circ} \mathrm{C}\right)$ could directly damage proteins and organelles and thus trigger cytoprotective autophagy to tolerate the cellular stresses and prolong the survival of cancer cells [45-47]. 


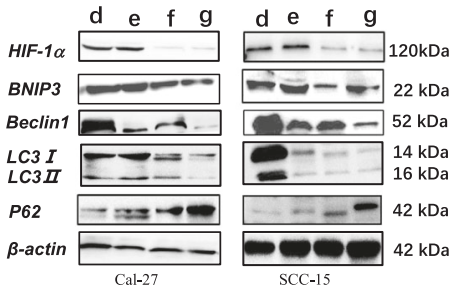

d: $H T+H y ; e: H T+H y+3-M A ; f: H T+H y+Y C-1$; g: $H T+H y+Y C-1+3-M A$. g: $H T+H y+Y C-1+3-M A$.
$H T:$ hyperthermia; $H y:$ hypoxia;

YC-1: 3-(5'-hydroxymethyl-2'-furyl)-1-benzylindazole;
(5) 3-MA: 3-Methyladenine.
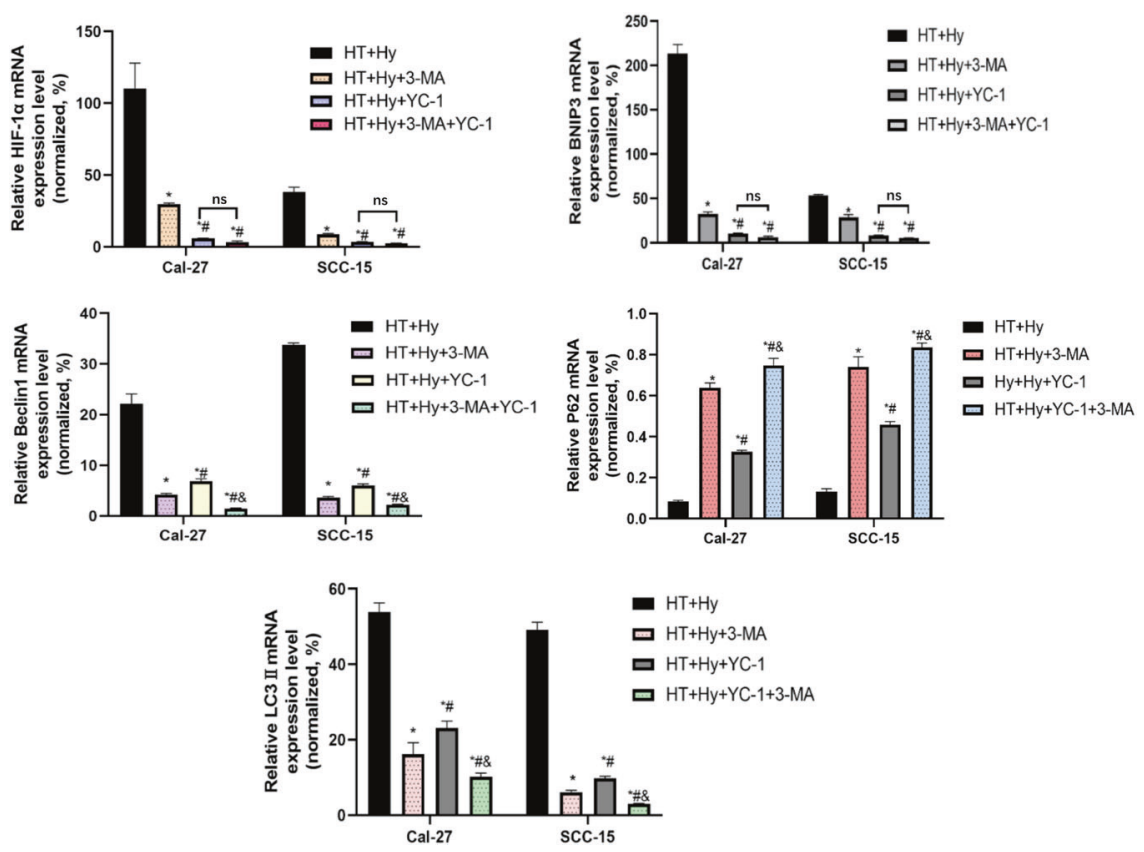

Fig. 5 The addition of YC-1 and 3-MA inhibited HT-induced autophagy in hypoxia and starvation tumor microenvironment, both of which involved downregulation of the HIF-1a/BNIP3 /Beclin1 signaling pathway. The mRNA and protein expression of HIF-1 $\alpha$, BNIP3, Beclin1, LC3-II, and p62 in OSCC cells were measured by Western blot and qRT-PCR, which were normalized to $\beta$-actin. The results were presented as the mean \pm standard deviation of three independent experiments. $\mathrm{d}$ : $\mathrm{HT}+\mathrm{Hy}$; e: $\mathrm{HT}+\mathrm{Hy}+3-\mathrm{MA} ; \mathrm{f}: \mathrm{HT}+\mathrm{Hy}+\mathrm{YC}-1 ; \mathrm{g}: \mathrm{HT}+\mathrm{Hy}$ +YC-1 + 3-MA. HT: hyperthermia; Hy: hypoxia; YC-1: 3-(5'-hydroxymethyl-2'-furyl)-1-benzylindazole; 3-MA: 3-Methyladenine. * $p<0.05$ vs. HT + Hy group; $\# p<0.05$ vs. HT + Hy $+3-M A$ group; $\& p<0.05$ vs. HT $+\mathrm{Hy}+\mathrm{YC}-1$ group; ns no significant difference $(p>0.05)$.

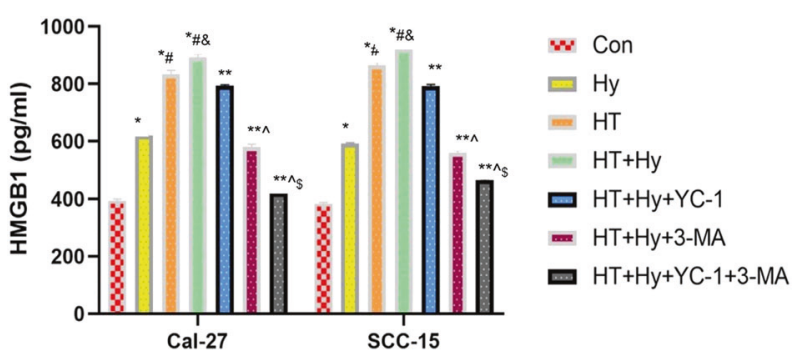

Fig. 6 HT combined YC-1, 3-MA alone or both inhibited the secretion of HMGB1 in Cal-27 and SCC-15 cells under hypoxia and starvation microenvironment as measured by ELISA. Data were presented as mean \pm SEM from three independent experiments. Con control, HT hyperthermia, Hy hypoxia, YC-1: 3-(5'-hydroxymethyl-2'furyl)-1-benzylindazole; 3-MA:3-methyladenine; ${ }^{*} p<0.05$ vs. Con group; \#p<0.05 vs. HT group; $\& p<0.05$ vs. Hy group; ${ }^{* *} p<0.05$ vs. $\mathrm{HT}+$ Hy group; $\wedge p<0.05$ vs. HT $+\mathrm{Hy}+3-\mathrm{MA}$ group; $\$ p<0.05$ vs. HT $+\mathrm{Hy}+$ YC-1 group; ns no significant difference $(p>0.05)$.

Literature reported that heat stress-induced autophagy in several types of cancer cells, such as hepatocellular carcinoma cells (SMMC7721 and Huh7), cervical cancer cell (HeLa), and lung cancer cell (A549 cell) [30, 43]. Our experimental data also indicated that hyperthermia could induce autophagy in both hypoxia and normoxic starvation microenvironments and that autophagy was further enhanced in hypoxia conditions. This might stem from the following reasons: HT-induced protein denaturation and aggregation results in the up-regulation of HSPs, which are reported to up-regulate the autophagy mediator Beclin1 [16]. Moreover, Hyperthermia can induce oxidative stress in cells and can further augment the generation of ROS [48]. ROS is a known inducer of autophagy and apoptosis. It has been reported that ROS acted on the complex formed by Beclin-1 and antiapoptotic $\mathrm{Bcl}-2$ homologs such as $\mathrm{BCl}-2$ and $\mathrm{Bcl}-\mathrm{xL}$. Moreover, this complex repressed the pro-autophagic activity of Beclin-1 and ROS could induce the dissociation of autophagy molecules Beclin 1 and $\mathrm{BCl}-2$, thus activating the Beclin1-induced autophagy pathway, increasing the expression of LC3-II, thereby initiating autophagy-associated pathways $[49,50]$. ROS is also reported to upregulate the activity of HIF1-a which facilitates the activation of the HIF1-a/BNIP3/Beclin1 autophagy signaling pathway. In our study, the expressions of Beclin1 and LC3-II significantly increased when cells were treated with hypoxia alone and increased even further when exposed to hyperthermia, which supported the above mechanism. Namely, HIF1-a/BNIP3/Beclin1 autophagy signaling pathway was activated under hypoxia conditions and hyperthermia further enhanced the activation of the pathway by secreting ROS.

And our research results demonstrated that cell migration was inhibited and cell apoptosis rate was significantly augmented when untreated or hypoxia-treated cells were exposed to hyperthermia. Existing literature shows that HMGB1 release occurs passively as cell permeability breaks down upon necrosis [51] and late stage of apoptosis [52]. And in our experimental results, the secretion of HMGB1 was upregulated by hyperthermia. Nevertheless, during tumor development and cancer therapy, HMGB1 has been reported to play paradoxical roles in promoting both cell survival and death by regulating multiple signaling pathways. It has been demonstrated HMGB1 increases pro-survival autophagy in a Beclin1-dependent way during chemotherapy [53]. Moreover, it has been demonstrated ATG5-mediated autophagy pathway promoted the secretion of HMGB1 in starvation and lipopolysaccharide treatment, and ROS signaling was required in this process [54]. What is more, several of the secondary messengers, such as cytosolic free calcium and ROS can regulate HMGB1 secretion [53]. We also demonstrated that both hyperthermia and hypoxia facilitated the secretion of HMGB1. Furthermore, previous research has confirmed that secreted HMGB1 activated receptors for advanced glycation end products and Toll-like receptor-4 and induced autophagy in skeletal muscle [55]. 
A

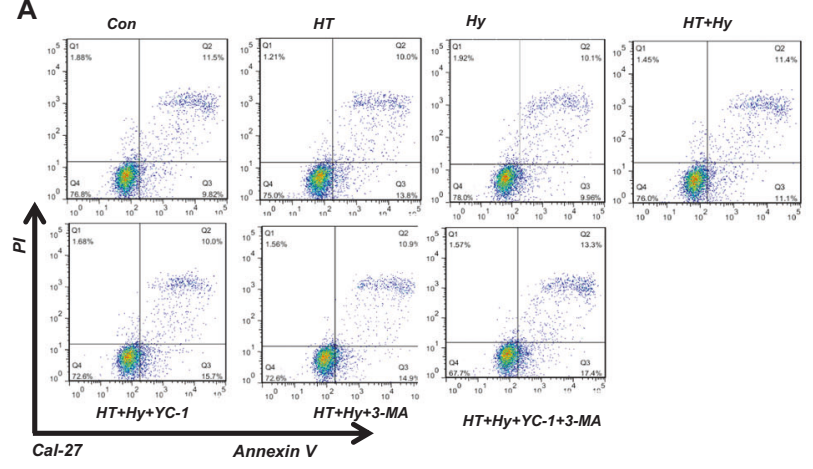

B

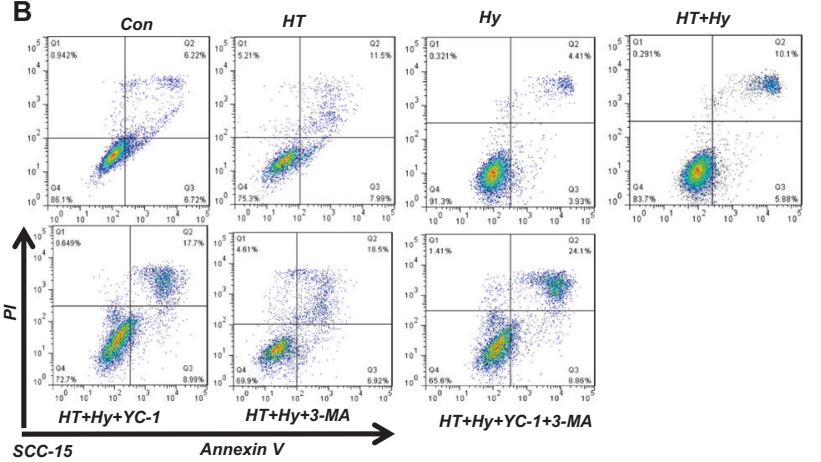

C Cal-27

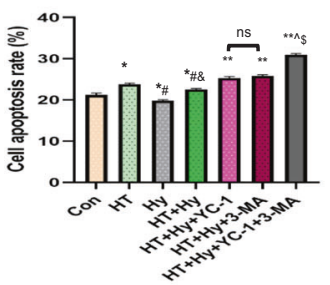

$\operatorname{SCC}-15$

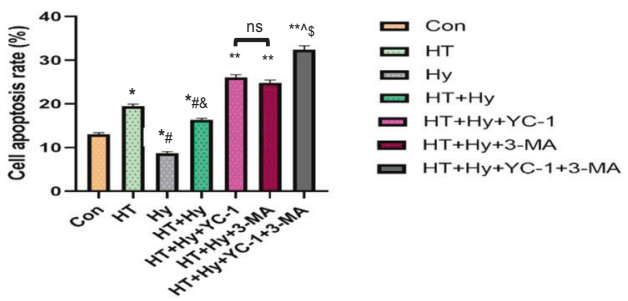

Fig. 7 HT combined YC-1, 3-MA alone or both facilitated the apoptosis of Cal-27 and SCC-15 cells in hypoxia and starvation microenvironment, as measured by flow cytometry. Data were presented as the mean \pm SEM from three independent experiments. Con control, HT hyperthermia, Hy hypoxia, YC-1: 3-(5'-hydroxymethyl-2'-furyl)-1-benzylindazole; 3-MA: 3-Methyladenine. The histogram of cell apoptosis rate after treatments were analyzed. ${ }^{*} p<0.05$ vs. Con group; $\# p<0.05$ vs. HT group; \& $<<0.05$ vs. Hy group; ${ }^{* *} p<0.05$ vs. HT + Hy group; $\wedge p<0.05$ vs. HT $+\mathrm{Hy}+3-\mathrm{MA}$ group; $\$ p<0.05$ vs. HT $+\mathrm{Hy}+\mathrm{YC}-1$ group; ns no significant difference $(p>0.05)$.

Recently, more and more researchers have paid attention to the manipulation of autophagy to enhance the efficacy of cancer therapy. YC-1 is a guanylate cyclase-activator and inhibitor of HIF1a [56] while 3-MA is a key drug in studying autophagy, which can block autophagy [57]. Therefore, we used YC-1 and 3-MA to examine the effect on autophagy. In the present study, we found the use of YC-1 significantly downregulated the expression of HIF$1 \mathrm{a}$ induced by $\mathrm{CoCl}_{2}$, although the exact mechanism is uncertain. We observed that inhibition of HIF-1a significantly suppressed BNIP3 expression and the administration of YC-1 and 3-MA alone or in combination significantly downregulated the expression of autophagy-related genes LC3II, Beclin1, and HMGB1, and increased the expression level of P62 when exposed to mild hyperthermia, hypoxia, and nutrition deficiency microenvironment. Furthermore, we found that $\mathrm{YC}-1$ and 3-MA treatment suppressed cell migration and increased cell apoptosis in Cal-27 and SCC-15 cell lines, which suggested that hyperthermia and hypoxia-induced a protective effect of autophagy by activating the HIF-1a/BNIP3/Beclin1 pathway and by stimulating the secretion of HMGB1, and autophagy act as a survival mechanism to alleviate hyperthermia and hypoxia injury. But even more importantly, this result could be reversed by the use of autophagy inhibitors and by blocking HIF-1a. Given the clinical application, when thermchemotherapy was used in combination, HT-related elevated blood perfusion also supported higher intra- and peritumoral drug concentrations, changed the tumor microenvironment to improve the efficacy of chemotherapy, while chemotherapy could effectively inhibit HT-induced autophagy to increase cell apoptosis. Autophagy and apoptosis are often inseparable and highly interactional. The research found that specifically blocking autophagy enabled ROS to increase significantly in malignant tumor cells. Thus, autophagy can aggravate the apoptosis of tumor cells [58]. The previous study shows that both apoptosis and autophagy are activated in response to metabolic stress [59], and accumulating evidence reveals that autophagy and apoptosis can cooperate, antagonize or assist each other, thus influencing the differential fate of the cell [60].

\section{CONCLUSIONS}

Although HT is considered to be a promising cancer treatment regimen, cellular damage caused by heating could be repaired and reversed by the production of HSPs and autophagy process in hypoxia and starving environment, resulting in incomplete cell necrosis and attenuating the effects of HT therapy. In this study, we demonstrated that exposure to hypoxia and hyperthermia could induce autophagy in the OSCC cells Cal-27 and SCC-15. This process could be reversed by the use of an autophagy inhibitor and by blocking HIF-1a. In summary, our findings might benefit a further understanding of the biological effects of thermo-chemo-therapy on cancer cells, and we believed that inhibition of autophagy might be a useful and promising therapeutic strategy to enhance the therapeutic effect of HT in hypoxia and nutrient deficiency tumor environments. In addition, further research on animal models is required in the future.

\section{MATERIAL AND METHODS}

\section{Human OSCC clinical samples}

The study was approved by the Ethics Committee of Yantai Yuhuangding Hospital and written informed consent was provided by all patients. OSCC and pare-cancer (tumor margin adjacent normal tissues) were obtained from 80 patients with primary OSCC, including 56 men and 24 women, aged 37-86 years, who underwent surgical resection of the tumor at the Yantai Yuhuangding Hospital between August 2015 and April 2017. None of the patients had received any chemotherapy or radiotherapy before excision. All samples were confirmed by pathological examination. The histological grade and tumor stage were assigned according to the World Health Organization (WHO) [61] and the International Union against Cancer classification system [62].

\section{Immunohistochemistry (IHC)}

The expression levels of HIF-1a and Beclin1 were analyzed by IHC. Briefly, antigen retrieval was performed by incubating the sections in $10 \mathrm{mM}$ citric acid buffer $(\mathrm{pH} 6.0)$ at $100^{\circ} \mathrm{C}$ for $15 \mathrm{~min}$. Subsequently, sections were dewaxed in xylene at room temperature and rehydrated in a descending ethanol series (absolute ethanol for $5 \mathrm{~min}, 95 \%$ ethanol for $5 \mathrm{~min}, 90 \%$ ethanol for $5 \mathrm{~min}$, and $80 \%$ ethanol for $5 \mathrm{~min}$ ). Following three washes with 
PBS-Tween (0.05\% Tween-20 in PBS), the sections were blocked by 5\% BSA (Sangon Biotech Co., Ltd., China) in TBS for $45 \mathrm{~min}$ at room temperature. The sections were subsequently incubated at $4{ }^{\circ} \mathrm{C}$ overnight with rabbit anti-HIF-1a or anti-Beclin1 polyclonal antibody diluted in 3\% BSA/TBS solution (1:100). The slides were washed with PBST and incubated with an HRP-conjugated goat anti-rabbit lgG secondary antibody (1:1000) at room temperature for $45 \mathrm{~min}$. The slides were subsequently stained with $3,3^{\prime}-$ diaminobenzidine tetrahydrochloride at room temperature for $10 \mathrm{~min}$, and then counterstained with $0.5 \%$ Harris' hematoxylin at room temperature for $5 \mathrm{~min}$. Finally, the sections were dehydrated with ethanol $(80 \%$ ethanol for $5 \mathrm{~min}, 90 \%$ ethanol for $5 \mathrm{~min}, 95 \%$ ethanol for $5 \mathrm{~min}$, and absolute ethanol for $5 \mathrm{~min}$ ), dried as well as mounted with neutral balsam. The images were screened using a microscope (magnification, $\times 100$ and $\times 400$ ). For scoring staining intensity, the expression level of HIF-1a and Beclin1 in TSCC tissues were evaluated using a numerical scale $(-$, negative; + , positive; ++ , moderate positive; +++ , strong positive; Fig. 1 ).

\section{Cell culture}

The human OSCC cell lines Cal-27 and SCC-15 were cultured in RPMI 1640 medium (Biological Industries, Israel), supplemented with $10 \%$ fetal bovine serum (FBS) (Gibco, Grand Island, USA) and $100 \mathrm{U} / \mathrm{ml}$ penicillinstreptomycin (Invitrogen, Carlsbad, USA), and maintained in a humidified atmosphere at $37^{\circ} \mathrm{C}$ with $5 \% \mathrm{CO}_{2}$. The following reagents were used in cell culture: 3-Methyladenine (3-MA) (Selleck, USA), 3-(5'-hydroxymethyl-2'furyl)-1-benzylindazole (YC-1) (Sigma, USA), Cobalt chloride $\left(\mathrm{CoCl}_{2}\right)$ (Solarbio, Beijing, China), which were dissolved with DMSO (Selleck, USA).

\section{Cell cytotoxicity and cell viability assay}

CCK-8 assay (Sangon, Shanghai, China) was used to detect the cytotoxic effect of different drug treatments on cancer cells and the $50 \%$ inhibitory concentration (IC50) of the drug was calculated. OSCC cells were plated into 96 -well plates with a density of $5 \times 10^{3}$ cells/well, supplied with $100 \mu \mathrm{L}$ complete growth medium. After $24 \mathrm{~h}$ incubation, cells were exposed to $\mathrm{CoCl}_{2}, \mathrm{YC}-1$, and 3-MA at the concentrations of $25 \mu \mathrm{M}$ to $200 \mu \mathrm{M}, 10 \mu \mathrm{M}$ to $100 \mu \mathrm{M}, 0.5 \mu \mathrm{M}$ to $150 \mu \mathrm{M}$, respectively. Untreated cells were used as control. At each time point, the cells were washed and incubated with 100ul RPMI 1640 plus $10 \mu \mathrm{L}$ CCK- 8 solution at $37^{\circ} \mathrm{C}$ for $3 \mathrm{~h}$. Subsequently, the absorbance was measured at $450 \mathrm{~nm}$ with a microplate reader (Bio Tek Instruments, Inc., USA). Each experiment was performed at least in triplicate. Dose-response curves were established to determine the IC50 values for $\mathrm{CoCl}_{2}, \mathrm{YC}-1$, and 3-MA in the two OSCC cell lines.

\section{Establishment of hypoxic environment and heat treatment}

A hypoxic environment was established by exposing cells to a serum-free medium with IC50 of $\mathrm{CoCl}_{2}$. Hyperthermia treatment was performed by partially submerging a cell culture flask in a thermostatically controlled circulating water bath (Shanghai Yiheng Scientific Instrument Co, LTD, China). Cells were treated at $42 \pm 0.1^{\circ} \mathrm{C}$ for $60 \mathrm{~min}$ and cool down to $37^{\circ} \mathrm{C}$ in less than $5 \mathrm{~min}$.

\section{RNA extraction and qRT-PCR}

Total RNA from cells was extracted with trizol reagent (Sangon, Shanghai, China). cDNA was synthesized by using PrimeScript ${ }^{\mathrm{TM}}$ RT Master Mix Kit (Takara, Japan). qRT-PCR was performed on a StepOne ${ }^{\text {TM }}$ Real-Time PCR System (Applied Biosystems, USA) with an SYBR Premix Ex Taq Kit (TaKaRa, Japan). According to the manufacturer's instructions, the PCRs were conducted at $95^{\circ} \mathrm{C}$ for $30 \mathrm{~s}$, followed by 40 cycles of $95^{\circ} \mathrm{C}$ for $3 \mathrm{~s}$, and $60^{\circ} \mathrm{C}$ for $30 \mathrm{~s}$. All reactions were performed in triplicate. The $2^{-\Delta \Delta C T}$ method was applied to calculate the relative fold change of gene expression. All results were normalized to GAPDH. Primer sequences (Sangon, Shanghai, China) were listed below: HIF-1a: up:5'-AGTTCCGCAAGCCCTGAAAGC-3', down:5'-GCAGTGGTAGTGGTGGCATTAGC-3'; Beclin1:up:5'-ATCTAAGGAGCTG CCGTTATAC-3', down:5'-CTCCTCAGAGTTAAACTGGGTT-3'; BNIP3: up:5'-AGG GCTCCTGGGTAGAACT-3'; down:5'-CTCCATTATAAATAGAAACCGAGGC-3'; GAPDH: up:5'-GCCACATCGCTCAGACACCA-3'; down:5'-TTCCCGTTCTCAGC CTTGAC-3'; LC3ll: up:5'-GTCAGCGTCTCCACACCAATCTC-3'; down:5'-TCC TGGGAGGCATAGACCATGTAC-3'; SQSTM1 (P62): up:5'-TGATTGAGTCCCTC TCCCAGATGC-3'; down:5'-CCGCTCCGATGTCATAGTTCTTGG-3'.

\section{Western blot}

Cells were collected and lysed in RIPA buffer (Beyotime, Shanghai, China). Total protein was quantified using the BCA kit (Beyotime, Shanghai,
China) according to the manufacturer's instructions. Subsequently, the proteins were separated by $10-12 \%$ SDS-PAGE and transferred to PVDF membranes (Bio-Rad Laboratories, Inc.), which were blocked with $10 \%$ nonfat milk and incubated with primary and secondary antibodies. Afterward, the protein bands were visualized with an ECL detection kit (Millipore, Burlington, MA) and analyzed using Image-Pro Plus 6.0 software (Media Cybernetics, Inc). The following antibodies were used: Beclin-1 (Cat. no.: NB500-249, Selleck, USA, 1:1000), HIF-1a (Cat. no.: BF8002, Bl, Israel, 1:1000), BNIP3 (Cat. no.: D221876, 1:1000), LC3B (Cat. no.: D163557,1:1500), SQSTM1/p62 (Cat. no.: sc-48402, 1:1500), mouse anti- $\beta$-actin monoclonal antibody (Cat. no.: MA1-744, 1:3000), mouse antiGAPDH monoclonal antibody (Cat. no.: SC-47724, Santa, USA, 1:2000), HRP-conjugated goat anti-mouse IgG antibody (Cat. no.: 31430, 1:3000) and HRP-conjugated goat anti-rabbit lgG antibody (Cat. no.: 314600, 1:3000). Antibodies were all obtained from Invitrogen, USA unless otherwise stated.

\section{Cell migration assay}

Cells were seeded in 6-well plates and cultivated until $100 \%$ confluence. In the serum-free RPIM 1640 medium, $100 \mu \mathrm{M} \mathrm{CoCl}_{2}$ was added to simulate a hypoxia environment, and cells were treated separately with $50 \mu \mathrm{M}$ 3-MA and/or $25 \mu \mathrm{M}$ YC-1 combined with heat treatment for $1 \mathrm{~h}$ in a $42^{\circ} \mathrm{C}$ water bath. Then the cells were scraped with $200 \mu \mathrm{L}$ of the pipette tip and washed with PBS three times. At 0 and $24 \mathrm{~h}$ after incubation in serum-free medium, the images of wound healing were captured using an inverted microscope (magnification, $\times 400$ ). The area of each wound was quantified using Image-Pro Plus 6.0 software (Media Cybernetics, Inc.). The cell migration rate (\%) was calculated as follows: [(Area of the wound at $0 \mathrm{~h} \mathrm{-}$ Area of the wound at $24 \mathrm{~h}$ )/Area of the wound at $0 \mathrm{~h}] \times 100 \%$.

\section{Flow cytometry analysis of apoptosis}

Cell apoptosis was detected by flow cytometry using the FITC-AnnexinV/ PI Apoptosis Assay Kit (BD, USA) following the manufacturer's instructions. Briefly, the cells $\left(5 \times 10^{5}\right.$ cells/well) that treated with chemotherapy (YC-1 and 3-MA) and hyperthermia $\left(42^{\circ} \mathrm{C}\right.$ heat treatment) were harvested and centrifuged at $500 \times \mathrm{g}$ for $5 \mathrm{~min}$ at room temperature, then washed twice with PBS and resuspended in $500 \mu \mathrm{L}$ binding buffer solution at a density of $1 \times 10^{5}$ cells $/ \mathrm{mL}$. The cells were subsequently stained with $5 \mu \mathrm{L}$ FITC Annexia V and $5 \mu \mathrm{L} \mathrm{PI} \mathrm{using} \mathrm{at} \mathrm{room} \mathrm{temperature}$ for $15 \mathrm{~min}$ in the darkness. Apoptotic cells were analyzed using a CytoFLEX flow cytometer and CytExpert software (version 2.0; Beckman Coulter, Inc.) within $1 \mathrm{~h}$.

\section{Enzyme-linked immunosorbent assay (ELISA)}

HMGB1 is passively released by necrotic tissues or actively secreted by stressed cells. To measure extracellular HMGB1, supernatants of cell culture were collected and centrifuged at $8000 \times 9$ for $5 \mathrm{~min}$ and immediately analyzed by enzyme-linked immunosorbent assay (ELISA) (Solarbio, Beijing, China) according to the manufacturer's instructions. The levels of HMGB1 in chemotherapy (YC-1 and 3-MA) and hyperthermia $\left(42{ }^{\circ} \mathrm{C}\right.$ heat treatment)-treated Cal-27 and SCC-15 cells that were in hypoxia and normoxia condition were determined using ELISA kits (llerite Biotechnology $\mathrm{Co}, \mathrm{China})$, in line with the manufacturer's protocol.

\section{Statistical analysis}

Statistical analysis was performed using the GraphPad Prism version 8.0 (GraphPad Software, La Jolla, CA). Data were presented as the mean \pm standard deviation, comparisons between groups were performed by using Student's $t$-test or a one-way ANOVA, followed by a Tukey's post hoc test for multiple comparisons. A $x^{2}$ test was used to determine the association between the expression levels of HIF-1a, Beclin1 respectively, and OSCC clinical and histopathological features. $p<0.05$ was considered a statistically significant difference Table 2.

\section{REFERENCES}

1. Matsuura D, Valim TD, Kulcsar MAV, Pinto FR, Brandão LG, Cernea CR, et al. Risk factors for salvage surgery failure in oral cavity squamous cell carcinoma. Laryngoscope. 2018;128:1113-9.

2. Zhang $K$, Zhou H, Yan B, Cao X. TUG1/miR-133b/CXCR4 axis regulates cisplatin resistance in human tongue squamous cell carcinoma. 2020;20:148.

3. Mangold AR, Torgerson RR, Rogers RS 3rd. Diseases of the tongue. Clin Dermatol. 2016;34:458-69. 
4. Graham K, Unger E. Overcoming tumor hypoxia as a barrier to radiotherapy, chemotherapy and immunotherapy in cancer treatment. Int J Nanomed. 2018;13:6049-58.

5. Masoud GN, Li W. HIF-1a pathway: role, regulation and intervention for cancer therapy. Acta Pharmaceut Sin B. 2015;5:378-89.

6. Henze AT, Mazzone M. The impact of hypoxia on tumor-associated macrophages. J Clin Investig. 2016;126:3672-9.

7. Wu CS, Chang IY, Hung JL, Liao WC, Lai YR, Chang KP, et al. ASC modulates HIF-1a stability and induces cell mobility in OSCC. Cell Death Dis. 2020;11:721.

8. Lepock JR. Role of nuclear protein denaturation and aggregation in thermal radiosensitization. Int J Hyperth. 2004;20:115-30.

9. Krenacs T, Meggyeshazi N, Forika G, Kiss E, Hamar P, Szekely T, et al. Modulated electro-hyperthermia-induced tumor damage mechanisms revealed in cancer models. Int J Mol Sci. 2020;21

10. Thanou M, Gedroyc W. MRI-guided focused ultrasound as a new method of drug delivery. J Drug Deliv. 2013;2013:616197.

11. Chiang CF, Hsu YH, Liu CC, Liang PC, Miaw SC, Lin WL. Pulsed-wave ultrasound hyperthermia enhanced nanodrug delivery combined with chloroquine exerts effective antitumor response and postpones recurrence. Sci Rep. 2019;9:12448.

12. Datta NR, Kok HP, Crezee H, Gaipl US, Bodis S. Integrating loco-regional hyperthermia into the current oncology practice: SWOT and TOWS analyses. Front Oncol. 2020;10:819.

13. Laha D, Deb M, Das H. KLF2 (kruppel-like factor 2 [lung]) regulates osteoclastogenesis by modulating autophagy. Autophagy. 2019;15:2063-75.

14. Kasprowska-Liśkiewicz D. The cell on the edge of life and death: crosstalk between autophagy and apoptosis. Postepy Hig. I Med. Doswiadczaln. 2017;71:825-41.

15. Liu C, Zhou X, Lu J, Zhu L, Li M. Autophagy mediates 2-methoxyestradiolinhibited scleroderma collagen synthesis and endothelial-to-mesenchymal transition induced by hypoxia. Rheumatology. 2019;58:1966-75.

16. Ahmed K, Zaidi SF, Mati Ur R, Rehman R, Kondo T. Hyperthermia and protein homeostasis: cytoprotection and cell death. J Therm Biol. 2020;91:102615.

17. Hurwitz M, Stauffer P. Hyperthermia, radiation and chemotherapy: the role of heat in multidisciplinary cancer care. Semin. Oncol. 2014;41:714-29.

18. Datta NR, Ordóñez SG, Gaipl US, Paulides MM, Crezee H, Gellermann J, et al. Local hyperthermia combined with radiotherapy and-/or chemotherapy: recent advances and promises for the future. Cancer Treat Rev. 2015;41:742-53.

19. Zhang Y, Calderwood SK. Autophagy protein aggregation and hyperthermia: a mini-review. Int J Hyperth. 2011;27:409-14.

20. Nivon M, Richet E, Codogno P, Arrigo AP, Kretz-Remy C. Autophagy activation by NFkappaB is essential for cell survival after heat shock. Autophagy. 2009;5:766-83

21. Chen T, Cen D, Ren Z, Wang Y, Cai X, Huang J, et al. Bismuth embedded silica nanoparticles loaded with autophagy suppressant to promote photothermal therapy. Biomaterials. 2019;221:119419.

22. Hwang JY, Gertner M, Pontarelli F, Court-Vazquez B, Bennett MV, Ofengeim D, et al. Global ischemia induces lysosomal-mediated degradation of mTOR and activation of autophagy in hippocampal neurons destined to die. Cell Death Differ. 2017;24:317-29.

23. Qu L, Chen C, Chen Y, Li Y, Tang F, Huang H, et al. High-mobility group box 1 (HMGB1) and autophagy in acute lung injury (ALI): a review. Med Sci Monit. 2019;25:1828-37.

24. Raucci A, Di Maggio S, Scavello F, D'Ambrosio A, Bianchi ME, Capogrossi MC. The Janus face of HMGB1 in heart disease: a necessary update. Cell Mol Life Sci. 2019;76:211-29.

25. Kang R, Chen R, Zhang Q, Hou W, Wu S, Cao L, et al. HMGB1 in health and disease. Mol Asp Med. 2014;40:1-116.

26. Kawahara I, Goto K, Kodama K, Luo Y, Fujiwara-Tani R, Mori T, et al. Magnetic hyperthermia using self-controlled heating elements consisting of Fe-Al milling alloy induces cancer cell apoptosis while preserving skeletal muscle. Pathobiology: J. Immunopathol. Mol. Cell. Biol. 2019;86:254-62.

27. Rouschop KM, Wouters BG. Regulation of autophagy through multiple independent hypoxic signaling pathways. Curr Mol Med. 2009;9:417-24.

28. Liu EY, Ryan KM. Autophagy and cancer-issues we need to digest. J Cell Sci. 2012;125:2349-58.

29. Powis G, Kirkpatrick L. Hypoxia inducible factor-1alpha as a cancer drug target. Mol Cancer Therapeut. 2004;3:647-54.

30. Gordan JD, Thompson CB, Simon MC. HIF and C-Myc: sibling rivals for control of cancer cell metabolism and proliferation. Cancer Cell. 2007;12:108-13.

31. Dang CV, Le A, Gao P. MYC-induced cancer cell energy metabolism and therapeutic opportunities. Clin Cancer Res. 2009;15:6479-83.

32. Nakashima R, Goto $Y$, Koyasu S, Kobayashi M, Morinibu A, Yoshimura M, et al. UCHL1-HIF-1 axis-mediated antioxidant property of cancer cells as a therapeutic target for radiosensitization. Sci Rep. 2017;7:6879.

33. Yoshida GJ. Metabolic reprogramming: the emerging concept and associated therapeutic strategies. J Exp Clin Cancer Res. 2015;34:111.
34. Rabinowitz JD, White E. Autophagy and metabolism. Science. 2010;330:1344-8.

35. Li YY, Feun LG, Thongkum A, Tu CH, Chen SM, Wangpaichitr M, et al. Autophagic mechanism in anti-cancer immunity: its pros and cons for cancer therapy. Int $J$ Mol Sci. 2017;18.

36. Marrero JA, Kudo M, Bronowicki JP. The challenge of prognosis and staging for hepatocellular carcinoma. Oncologist. 2010;15:23-33.

37. Venereau $E$, Casalgrandi M, Schiraldi M, Antoine DJ, Cattaneo A, De Marchis F, et al. Mutually exclusive redox forms of HMGB1 promote cell recruitment or proinflammatory cytokine release. J Exp Med. 2012;209:1519-28.

38. Ribeiro M, Teixeira SR, Azevedo MN, Fraga AC Jr., Gontijo AP, Vêncio EF Expression of hypoxia-induced factor- 1 alpha in early-stage and in metastatic oral squamous cell carcinoma. Tumour Biol. 2017;39:1010428317695527.

39. Yu L, Chen Y, Tooze SA. Autophagy pathway: cellular and molecular mechanisms. Autophagy. 2018;14:207-15.

40. Xilouri M, Brekk OR, Polissidis A, Chrysanthou-Piterou M, Kloukina I, Stefanis L. Impairment of chaperone-mediated autophagy induces dopaminergic neurodegeneration in rats. Autophagy. 2016;12:2230-47.

41. Priolo C, Pyne S, Rose J, Regan ER, Zadra G, Photopoulos C, et al. AKT1 and MYC induce distinctive metabolic fingerprints in human prostate cancer. Cancer Res. 2014;74:7198-204.

42. Jones NP, Schulze A. Targeting cancer metabolism-aiming at a tumour's sweetspot. Drug Discov Today. 2012;17:232-41.

43. Mizushima N, Yoshimori T, Levine B. Methods in mammalian autophagy research. Cell. 2010;140:313-26.

44. Schiraldi M, Raucci A, Muñoz LM, Livoti E, Celona B, Venereau E, et al. HMGB1 promotes recruitment of inflammatory cells to damaged tissues by forming a complex with CXCL12 and signaling via CXCR4. J Exp Med. 2012;209:551-63.

45. Jiang J, Chen S, Li K, Zhang C, Tan Y, Deng Q, et al. Targeting autophagy enhances heat stress-induced apoptosis via the ATP-AMPK-mTOR axis for hepatocellular carcinoma. Int J Hyperth. 2019;36:499-510.

46. Wu X, Wu Y, Wang Z, Liu L, Sun C, Chen Y, et al. A cascade-targeting nanocapsule for enhanced photothermal tumor therapy with aid of autophagy inhibition. Adv Healthc Mater. 2018;7:e1800121.

47. Wan HY, Chen JL, Zhu X, Liu L, Wang J, Zhu XM. Titania-coated gold nanobipyramids for blocking autophagy flux and sensitizing cancer cells to proteasome inhibitor-induced death. Adv Sci. 2018;5:1700585.

48. Yang $Y$, Yang $C L$, Zhao ZJ, Zuo $X X$, Liang $T S$, Yang $Y$, et al. Microwave hyperthermia enhances the sensitivity of lung cancer cells to gemcitabine through reactive oxygen species-induced autophagic death. Oncol Rep. 2019;41:3100-10.

49. Ba MC, Long H, Cui SZ, Gong YF, Yan ZF, Wang S, et al. Mild hyperthermia enhances sensitivity of gastric cancer cells to chemotherapy through reactive oxygen species-induced autophagic death. Tumour Biol. 2017;39:1010428317711952.

50. Wu Y, Pan M, Cui S, Ba M, Chen Z, Ruan Q. Autophagic death induced by thermo-chemotherapy in gastric cancer cells results from the reactive oxygen species pathway. Mol Med Rep. 2016;14:1210-8.

51. Scaffidi $P$, Misteli T, Bianchi ME. Release of chromatin protein HMGB1 by necrotic cells triggers inflammation. Nature. 2002;418:191-5.

52. Bell CW, Jiang W, Reich CF 3rd, Pisetsky DS. The extracellular release of HMGB1 during apoptotic cell death. Am J Physiol Cell Physiol. 2006;291:C1318-1325.

53. Kang R, Zhang Q, Zeh HJ 3rd, Lotze MT, Tang D. HMGB1 in cancer: good, bad, or both? Clin Cancer Res. 2013;19:4046-57.

54. Dupont N, Jiang S, Pilli M, Ornatowski W, Bhattacharya D, Deretic V. Autophagybased unconventional secretory pathway for extracellular delivery of IL-1 $\beta$. EMBO J. 2011;30:4701-11.

55. Luo Y, Yoneda J, Ohmori H, Sasaki T, Shimbo K, Eto S, et al. Cancer usurps skeletal muscle as an energy repository. Cancer Res. 2014;74:330-40.

56. Lin YS, Shen YJ, Ou PH, Lai CJ. HIF-1a-mediated, NADPH oxidase-derived ROS contributes to laryngeal airway hyperreactivity induced by intermittent hypoxia in rats. Front Physiol. 2020;11:575260.

57. Bao Y, Ding Z, Zhao P, Li J, Chen $P$, Zheng J, et al. Autophagy inhibition potentiates the anti-EMT effects of alteronol through TGF- $\beta / S$ mad3 signaling in melanoma cells. Cell Death Dis. 2020;11:223.

58. Wang K. Autophagy and apoptosis in liver injury. Cell Cycle. 2015;14:1631-42.

59. Liang J, Shao SH, Xu ZX, Hennessy B, Ding Z, Larrea M, et al. The energy sensing LKB1-AMPK pathway regulates p27(kip1) phosphorylation mediating the decision to enter autophagy or apoptosis. Nat Cell Biol. 2007;9:218-24.

60. Nikoletopoulou V, Markaki M, Palikaras K, Tavernarakis N. Crosstalk between apoptosis, necrosis and autophagy. Biochim Biophys Acta. 2013;1833: 3448-59.

61. Katabi N, Lewis JS. Update from the 4th edition of the World Health Organization classification of head and neck tumours: what is new in the 2017 WHO blue book for tumors and tumor-like lesions of the neck and lymph nodes. Head Neck Pathol. 2017;11:48-54. 
12

62. Monden N, Asakage T, Kiyota N, Homma A, Matsuura K, Hanai N, et al. A review of head and neck cancer staging system in the TNM classification of malignant tumors (eighth edition). Jpn J Clin Oncol. 2019, 49:589-95.

\section{ACKNOWLEDGEMENTS}

All authors read and approved the final manuscript. This project was supported by the Yantai Science and Technology Project of Shandong Province in China (2018SFGY106).

\section{FUNDING}

This project was supported by the Yantai Science and Technology Project of Shandong Province in China.

\section{CONFLICT OF INTEREST}

The authors declare no competing interests.

\section{ADDITIONAL INFORMATION}

Supplementary information The online version contains supplementary material available at https://doi.org/10.1038/s41420-021-00538-5.
Correspondence and requests for materials should be addressed to S.W.

Reprints and permission information is available at http://www.nature.com/ reprints

Publisher's note Springer Nature remains neutral with regard to jurisdictional claims in published maps and institutional affiliations.

cC (i) Open Access This article is licensed under a Creative Commons cc) Attribution 4.0 International License, which permits use, sharing, adaptation, distribution and reproduction in any medium or format, as long as you give appropriate credit to the original author(s) and the source, provide a link to the Creative Commons license, and indicate if changes were made. The images or other third party material in this article are included in the article's Creative Commons license, unless indicated otherwise in a credit line to the material. If material is not included in the article's Creative Commons license and your intended use is not permitted by statutory regulation or exceeds the permitted use, you will need to obtain permission directly from the copyright holder. To view a copy of this license, visit http://creativecommons. org/licenses/by/4.0/.

(c) The Author(s) 2021 